\title{
Structural and Cellular Analyses of Cancer-Associated Mutations in DNA Repair Enzymes
}

\author{
Brian E. Eckenroth ${ }^{a}$, Ash Prakash ${ }^{\mathrm{c}}$, Brittany L. Carroll ${ }^{\mathrm{a}}$, Joann B. Sweasy ${ }^{\mathrm{b}}$, and Sylvie Doublié ${ }^{\mathrm{a}}$ \\ ${ }^{a}$ Dept. of Microbiology and Molecular Genetics, University of Vermont, Burlington, VT 05405 \\ ${ }^{b}$ Dept. of Therapeutic Radiology, Yale University School of Medicine, New Haven, CT 06520 \\ ${ }^{\mathrm{c} N e w}$ address: University of South Alabama Mitchell Cancer Institute, Mobile, AL 36604-1405 \\ Email contact: sdoublie@uvm.edu
}

Base excision repair (BER) is a class of DNA repair that is conserved across all organisms and is essential for life. BER proteins remove oxidized DNA bases and minimize genome instability. We have found that DNA repair protein variants can lead to aberrant BER, and the following consequences: increased genome damage, cell transformation, and cancer. Large-scale sequencing of human tumor and germline DNA revealed numerous rare mutations in BER proteins. We use biochemical, cellular, and structural biology approaches to determine whether such BER variants give rise to aberrant DNA repair and carcinogenesis. The NEIL1, NEIL2, and NEIL3 glycosylases specialize in repairing oxidized bases in different DNA structure contexts. We will present our latest results on variants of these glycosylases. For example, our work on a NEIL1 cancerassociated variant (G83D) showed that the mutant enzyme is unable to repair DNA lesions such as thymine glycol. A crystal structure of the variant indicated that this enzyme would likely be hampered in the search of lesions in DNA [1]. Later on, expression of G83D variant in human cells was shown to induce genomic instability and cellular transformation [2]. Taken together, these results are consistent with the concept that unrepaired oxidative damage at the replication fork can lead to genomic instability and mutagenesis. The functional characterization of SNPs and somatic variants will provide a better understanding into an underappreciated initiator of cancer, generate insight into the mechanism of BER DNA repair enzymes in human cells, and inform the treatment of individual cancers.

\section{$\underline{\text { References }}$}

[1] Prakash A., Carroll B.L., Sweasy J.B., Wallace S.S. and Doublié S. (2014) Genome and Cancer Single Nucleotide Polymorphisms of the Human NEIL1 DNA Glycosylase: Activity, Structure, and the Effect of Editing. DNA Repair. 14:1726 PMCID: PMC3926126

[2] Galick HA, Marsden CG, Kathe S, Dragon JA, Volk L, Nemec AA, Wallace SS, Prakash A, Doublié S, Sweasy JB. (2017) The NEIL1 G83D germline DNA glycosylase variant induces genomic instability and cellular transformation. Oncotarget 8:85883-85895 PMCID: PMC5689654 